\title{
Multiplex Real-Time Quantitative PCR to Detect and Quantify Verticillium dahliae Colonization in Potato Lines that Differ in Response to Verticillium Wilt
}

\author{
Z. K. Atallah, J. Bae, S. H. Jansky, D. I. Rouse, and W. R. Stevenson
}

First, fourth, and fifth authors: Department of Plant Pathology, University of Wisconsin, Madison 53706; second author: Department of Horticulture, University of Wisconsin, Madison 53706; and third author: United States Department of Agriculture-Agricultural Research Service, Vegetable Crops Research Unit, University of Wisconsin, Madison 53706. Accepted for publication 5 February 2007.

\begin{abstract}
Atallah, Z. K., Bae, J., Jansky, S. H., Rouse, D. I., and Stevenson, W. R. 2007. Multiplex real-time quantitative PCR to detect and quantify Verticillium dahliae colonization in potato lines that differ in response to Verticillium wilt. Phytopathology 97:865-872.

Potato early dying (PED), also known as Verticillium wilt, caused by Verticillium dahliae, is a seasonal yield-limiting disease of potato worldwide, and PED-resistant cultivars currently represent only a small percentage of potato production. In this study, we developed a real-time quantitative polymerase chain reaction (Q-PCR) approach to detect and quantify $V$. dahliae. The efficiency of the designed primer pair VertBt$\mathrm{F} /$ VertBt-R, derived from the sequence of the $\beta$-tubulin gene, was greater than $95 \%$ in monoplex Q-PCR and duplex (using Plexor technology)

procedures with primers PotAct-F/PotAct-R, obtained from the sequence of the actin gene, designed for potato. As few as $148 \mathrm{fg}$ of $V$. dahliae DNA were detected and quantified, which is equivalent to five nuclei. QPCR detected $V$. dahliae in naturally infected air-dried potato stems and fresh stems of inoculated plants. Spearman correlations indicated a high correlation (upward of $80 \%$ ) between $V$. dahliae quantifications using QPCR and the currently used plating assays. Moreover, Q-PCR substantially reduced the variability compared with that observed in the plating assay, and allowed for the detection of $V$. dahliae in $10 \%$ of stem samples found to be pathogen free on the culture medium. The described Q-PCR approach should provide breeders with a more sensitive and less variable alternative to time-consuming plating assays to distinguish response of breeding lines to colonization by $V$. dahliae.
\end{abstract}

Potato early dying (PED), also known as Verticillium wilt, is a persistent disease of potato (Solanum tuberosum) and is considered by many to be the major yield-limiting biotic factor in the irrigated regions of potato production in the United States $(46,48,49)$. PED is caused most commonly by the ubiquitous soilborne fungus Verticillium dahliae, either alone or in a synergistic interaction with the nematode Pratylenchus penetrans $(29,30,46$, $48,49)$. The disease leads to a reduction in leaf area $(2,51)$ and premature senescence of potato plants, which shortens the period of tuber bulking, subsequently reducing yields. Yield losses associated with PED may reach $50 \%$, but are more commonly in the range of 10 to $15 \%(46,48,49)$.

Verticillium wilt is a monocyclic disease, and the pathogen survives between growing seasons as microsclerotia, which also serve as the principal means for pathogen dispersal on seed tubers, farm equipment, and in soil and water. Currently, PED is controlled mainly through fumigation in fields previously planted to potato, extended crop rotations, or by planting in fields never previously planted with potato ("virgin land"). A few potato cultivars (e.g., Ranger Russet and Bannock Russet) exhibit resistance to $V$. dahliae in the field, but currently represent a small percentage of the total U.S. area planted to potato, the majority of which is planted to susceptible cultivars (e.g., Russet Burbank and Russet Norkotah). Several wild and interspecific hybrids of Solanum spp. show significant levels of resistance to PED and currently are being investigated as sources of resistance $(26-28,34)$.

Corresponding author: Z. K. Atallah; E-mail address: atila@plantpath.wisc.edu

doi:10.1094/PHYTO-97-7-0865

(c) 2007 The American Phytopathological Society
Commonly, the assessment of the response of potato breeding lines to PED is based on the colonization of plant tissues by $V$. dahliae. Indeed, numerous currently grown potato cultivars were selected based on the quantification of $V$. dahliae propagules in plant material $(6,14,25-28,38,39,62)$, which relies on the use of semiselective culture media such as Tergitol-NPX (NPX) (6). The number of colonies of $V$. dahliae observed on the NPX medium 2 weeks after transfer is translated into the number of CFU, which is used as a quantitative measure of plant colonization $(6,14,25-$ $28,38,39,62)$. Although the detection of the pathogen in plant tissues is improved using polymerase chain reaction (PCR) methodologies compared with the culture medium assay $(13,33,35-37)$, quantification is tedious and ambiguous (36). Alternatively, realtime quantitative-PCR (Q-PCR) allows for a simpler quantification, in addition to an increased sensitivity compared with conventional PCR assays $(1,11,12,53,60,63,64)$.

Sequences of the internally transcribed spacer region (ITS) of the ribosomal DNA (rDNA) often are used to design PCR and QPCR primers to detect different fungal pathogens in potato tissues $(11,12,32,47,56-58)$. Such targets with high copy numbers make the amplification and detection of fungal pathogens using PCR easy and reliable. However, the number of rDNA copies fluctuates with the age and stage of growth of the organism (44). Furthermore, nonorthologous copies of the ITS region within species and among strains within the same species are described in the literature (31). Such inconsistencies may affect the quantification of pathogen propagule numbers and potential comparisons among samples. Single-copy nuclear genes would provide specific primers, allowing for consistent pathogen quantifications regardless of age and growth stage.

The objective of this study was to develop a $V$. dahliae quantification methodology based on Q-PCR which can provide higher 
sensitivity, accuracy, and specificity compared with the NPX plating assay. The ability to detect and quantify pathogenic propagules soon after infection and prior to the appearance of PED symptoms would provide breeders with a tool to accelerate the selection process for resistance to PED and reduce the variability arising from plating assays.

\section{MATERIALS AND METHODS}

Isolate collection. DNA from $45 \mathrm{~V}$. dahliae isolates, 9 other Verticillium spp., 17 Fusarium spp., and isolates of 10 different pathogens of potato or crops used in the rotation with potato was used to develop the intended Q-PCR primers. The $V$. dahliae isolates were chosen from various geographic locations (in the United States and other countries) and various hosts. A subset of isolates used to validate the specificity of the designed primer pairs is shown in Table 1. All Verticillium spp. DNA samples were obtained from the collection of D. I. Rouse and were used by Li et al. (33). All other DNAs were obtained by growing individual fungal and oomycete isolates in clarified V8 broth, prior to extracting DNA with FastDNA kit (MP Biomedicals, Irvine, CA), following the manufacturer's recommendations. DNA samples were quantified fluorometrically using Quant-IT PicoGreen double-stranded (ds)DNA (Invitrogen, Carlsbad, CA) and stored at $4^{\circ} \mathrm{C}$ until used.

Primer design. Sequences of functional protein-coding genes were generated for the purpose of designing primers specific for $V$. dahliae by sequence comparative analyses. Universal primer pairs were used to amplify fragments of six genes from DNA of 81 fungal and oomycetous isolates in the abovementioned collection. Those genes were elongation factor $1 \alpha($ efl $\alpha)$, calmodulin (cal), actin (act), $\beta$-tubulin 1 and 2, histone 3 (H3), and histone 4 (H4) $(7,22)$. The sequences of these central function genes typically are highly conserved within species but polymorphic among species and genera. For the purposes of this study, only the sequences exhibiting polymorphisms that specifically differentiate $V$. dahliae from other species (most especially within the genus Verticillium) will be discussed hereafter.

PCR amplifications were conducted in a Bio-Rad iCycler thermocycler (Hercules, CA), one-half degree lower than the calculated melting temperature for the primers to maximize amplification specificity as predicted by Primer3 (50). The 20- $\mu$ l amplification reactions included $1 \mathrm{ng}$ of total purified culture DNA and $200 \mathrm{nM}$ each primer, in Promega PCR Master Mix (Promega Corp., Madison, WI) (1.5 mM $\mathrm{MgCl}_{2}, 200 \mathrm{nM}$ each dNTPS, and Taq Polymerase at $25 \mathrm{U} / \mathrm{ml})$. Amplification products were visual-

TABLE 1. List of fungi, oomycetes, and bacteria used to design and evaluate primer pair VertBt-F/VertBt-R designed for the specific detection and quantification of Verticillium dahliae ${ }^{\mathrm{a}}$

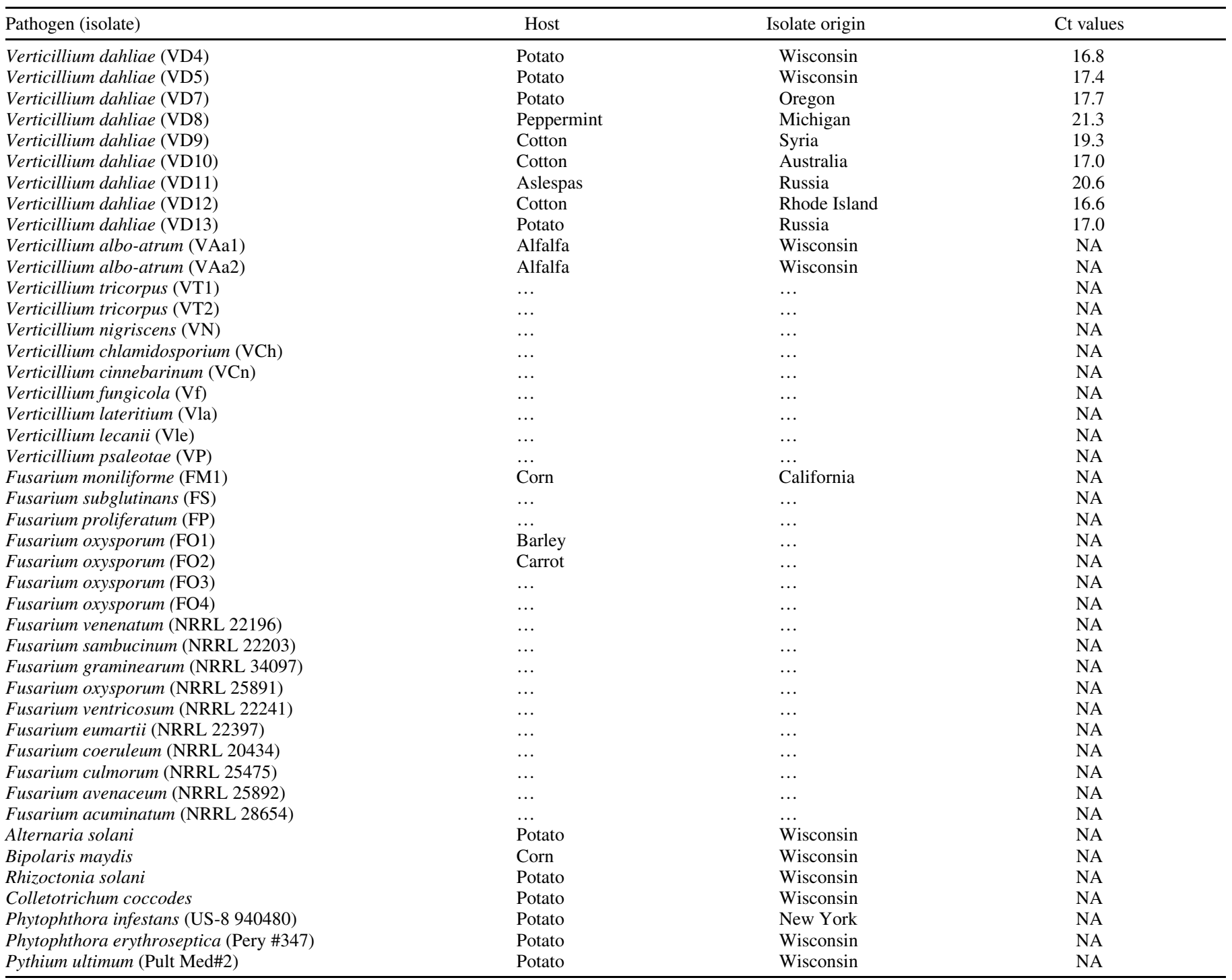

${ }^{a}$ Cycle threshold $(\mathrm{Ct})$ values of the real-time quantitative polymerase chain reaction assay also are listed. NA $=$ no amplification and $\ldots=$ information not available to authors. 
ized in $0.8 \%$ agarose gels. Both DNA strands of products smaller than 700 bp were sequenced directly. PCR-amplified products were cleaned using AMPure magnetic beads (Agencourt, Beverly, MA) prior to labeling using ABI BigDye Terminator (version 3.1; Applied Biosystems; Foster City, CA), and excess labeling dyes was removed with CleanSEQ magnetic beads (Agencourt). Amplification products in excess of $700 \mathrm{bp}$ were cloned prior to sequencing (in both directions) in the Topo TA Cloning kit (Invitrogen). Sequencing was performed at the University of Wisconsin Biotechnology Center, using the ABI 3730xl DNA Analyzer. Sequences were visualized in Chromas (Technelysium, Southport, Queensland, Australia), aligned using Clustal W $(54,55)$, and the consensus sequence was edited in BioEdit (23).

Sequences from the target organisms, related species, genera, and other pathogens of potato and rotational crops were aligned in Clustal W. Primers were designed from areas polymorphic among species of the genus Verticillium, yet monomorphic within $V$. dahliae. Prospective primer sequences were evaluated using Primer3 to assess potential self-compatibility, melt temperatures, and gas chromatography clamping. Subsequently, candidate primers and amplicons were evaluated in Mfold (65) for potential secondary structures, which would reduce amplification efficiency. Moreover, care was taken to obtain primers for $V$. dahliae that could be duplexed with preexisting primers designed for the quantification potato DNA (1).

Evaluation of primer specificity. Primer specificity was tested using DNA from a subsample of the collection described above (Table 1). Q-PCR amplifications were conducted in triplicate on a Bio-Rad iCycler iQ real-time PCR system using the iQ Supermix SYBR-Green (Bio-Rad) with $\approx 1 \mathrm{ng}$ of DNA and $200 \mathrm{nM}$ each primer in $20 \mu \mathrm{l}$ of total volume. The following amplification protocol was used: initial denaturation of $3 \mathrm{~min}$ at $95^{\circ} \mathrm{C}$, followed by 40 cycles of $95^{\circ} \mathrm{C}$ for $10 \mathrm{~s}$ and $63^{\circ} \mathrm{C}$ (identified following temperature gradient amplifications) for $45 \mathrm{~s}$. Melt curve analysis was used to distinguish potential primer dimers and nonspecific amplification products.

Primer efficiency. Amplification efficiency (efficiency = $\left.10^{(-1 / \text { slope })}-1\right)$ of each primer pair was tested on a sixfold serial dilution of $V$. dahliae DNA, starting at a concentration $14.8 \mathrm{ng} / \mu \mathrm{l}$, with $1 \mu \mathrm{l}$ of DNA added to a $20-\mu \mathrm{l}$ Q-PCR reaction. Amplifications of $V$. dahliae target DNA were performed in the presence and in the absence of potato DNA. Potato DNA (25 ng) extracted from a disease-free and surface-disinfested tuber was added to the serial dilution of $V$. dahliae DNA. Q-PCR efficiencies were calculated using the Bio-Rad iCycler software (version 3.1). To determine the potential impact of the addition of potato DNA on the amplification of the target DNA, the slopes of the efficiency equations were compared using an analysis of covariance (ANCOVA) using PROC GLM in SAS (v. 9.0; SAS Institute, Cary, NC). Equations with similar slopes result in $F$ statistics $>1$, indicating that variability is greater within an equation compared with between equations (8).

Field samples. Clones of various Solanum hybrids were planted at the University of Wisconsin Hancock Agricultural Experiment Station on Plainfield loamy sand soil (92\% sand, 5\% silt, $3 \%$ clay, and $<1 \%$ organic matter) in a field routinely used to screen for resistance to $V$. dahliae in potato cultivars and breeding lines. This field has been planted continuously to potato for nearly 40 years and contains $\approx 50 \mathrm{CFU}$ of $V$. dahliae per gram of soil. Additionally, ground rye seed infested with $V$. dahliae VCG4A isolate V18 were buried in the furrow with each tuber seed piece at planting (9 May 2005). Isolate V18 is a highly aggressive strain of $V$. dahliae that was isolated from severely affected potato plants in the same field and was used successfully in numerous studies of PED both in the field and in the greenhouse $(2,3,26-$ $28,33,43,52)$.

To generate the $V$. dahliae isolate V18 inoculum, rye kernels were soaked in distilled water overnight, drained, placed in a mush- room bag $(1 \mathrm{~kg} / \mathrm{bag})$, and autoclaved twice $\left(121^{\circ} \mathrm{C}\right.$ for $70 \mathrm{~min}$ on two consecutive days). Subsequently, the bags were inoculated with $10 \mathrm{ml}$ of a suspension of isolate V18 $\left(6 \times 10^{6}\right.$ conidia $\left./ \mathrm{ml}\right)$, incubated for 2 months, and air dried. A Wiley mill with a 60-mesh screen was used to grind the colonized rye kernels to a powder with an infestation level of $200 \mathrm{CFU} / \mathrm{g}$.

The planted potato plots were irrigated three times weekly. When plants appeared to be within 1 week of senescence, the basal portions of 112 stems measured from ground level to $\approx 10 \mathrm{~cm}$ up the stem were collected and air dried in order to measure colonization by $V$. dahliae. Air-dried basal stem segments were ground in a Wiley mill and separated into four 50-mg aliquots. Two 50-mg aliquots of each stem were plated on NPX medium (6) and colonies of $V$. dahliae were counted under a dissecting microscope after incubation for 2 weeks in the dark at room temperature. The remaining two ground stem 50-mg aliquots were used to extract DNA.

Greenhouse samples. In all, 12 plants of potato cv. Ranger Russet (PED resistant) and 12 plants of cv. Russet Norkotah (PED susceptible) were grown in the greenhouse. Nuclear seed of each cultivar was planted (10 February 2006) in a 1:1 vol/vol vermiculite and commercial potting mix. One week after emergence (7 March 2006), the plantlets were carefully removed from the pot and dipped for $10 \mathrm{~min}$ in a suspension $\left(8 \times 10^{6}\right.$ conidia $\left./ \mathrm{ml}\right)$ of $V$. dahliae (isolate V18). Each plantlet then was transferred to a $15-\mathrm{cm}$ pot filled with the soil mix described above. Growing conditions were $25 \pm 2{ }^{\circ} \mathrm{C}$ during the day and $18 \pm 2^{\circ} \mathrm{C}$ at night, with a 16-h photoperiod. Plants were watered as needed and fertilized at the time of transplanting to the commercial potting mix using 20-20-20 commercial fertilizer (J.R. Peters, Allentown, PA). Two untreated control plants of each cultivar were dipped in water and otherwise treated similarly to the other plants in the trial. Furthermore, other plants of each of the two cultivars also were inoculated with $V$. dahliae isolate V18 and treated similarly, but were raised to maturity, along with noninoculated checks, to confirm expression of typical PED symptoms.

Four weeks after inoculation, a 5-cm-long portion at the base of the stem of each plant was excised, cut into small pieces, and divided into two groups. The crown in one group was squeezed to release the sap, which was used for the plating assay. For this assay, two $50-\mu l$ aliquots of the squeezed sap were spread onto NPX medium. Colony counting was completed after a 2-week incubation in the dark, at room temperature. A second group of crowns was ground in liquid nitrogen, using a mortar and pestle, and two 50-mg aliquots were used to extract DNA.

DNA extraction. All DNA samples were extracted using the FastDNA kit, using the manufacturer's recommendations. Subsequently, DNA extracts were cleaned up using the AMPure magnetic beads to eliminate remaining potential PCR inhibitors. All DNA samples were quantified fluorometrically using Quant-IT PicoGreen dsDNA and stored at $4{ }^{\circ} \mathrm{C}$.

Q-PCR amplifications. Q-PCR amplifications were conducted in triplicate (total of six amplifications performed on each stem), in a Bio-Rad iCycler iQ real-time PCR system using the iQ Supermix SYBR-Green (Bio-Rad) with $\approx 1 \mathrm{ng}$ of DNA and $200 \mathrm{nM}$ each primer in $20 \mu \mathrm{l}$ of total volume. The following amplification protocol was used: initial denaturation of $3 \mathrm{~min}$ at $95^{\circ} \mathrm{C}$, then 40 cycles of $95^{\circ} \mathrm{C}$ for $10 \mathrm{~s}$ and $63^{\circ} \mathrm{C}$ for $35 \mathrm{~s}$. Melt curve analysis was used to distinguish potential primer dimers and nonspecific amplification products. The absence of PCR inhibitors in DNA samples was assessed by spiking each DNA sample with 10 pg of Phytophthora infestans DNA (isolate US-8 940480) and computing the cycle threshold $(\Delta \mathrm{Ct})$ value $\left(\Delta \mathrm{Ct}=\mathrm{Ct}_{\text {sample }}-\mathrm{Ct}_{\text {control }}\right)(21)$. No natural infections with $P$. infestans have been observed in Wisconsin since the 2002 growing season. In all amplifications, DNA from pure cultures of each $V$. dahliae was used as the positive control and a no-template water sample as the negative control. The infection coefficient (IC), which is the ratio of $\mathrm{Ct}_{\text {host }} / \mathrm{Ct}_{\text {pathogen }}$ 
(59), was computed for each sample tested. The amounts of potato DNA were quantified using the primer pair PotAct-F/PotAct$\mathrm{R}$, designed to amplify the act gene in potato (GenBank accession no. X55751), as previously described (1).

A duplex Q-PCR assay of the selected two primer pairs was developed using Plexor Q-PCR System (Promega Corp.). Unlike the SYBR-Green assay, in which the incorporation of the fluorescent dye increases with the increasing number of copies of the DNA target, Plexor leads to a quenching of the dye and a reduction in fluorescence over time (20). One of the two primers is labeled with a fluorescent dye and modified with methylisocytosine (iso$\mathrm{dC}$ ) residue at the $5^{\prime}$ end, whereas the other primer is not. The dabcyl-iso-dGTP (iso-dG) present in the Q-PCR reaction mixture then is incorporated at the position complementary to the iso-dC label, effectively quenching the fluorescence over time. Primers VertBt-R and PotAct-R were labeled with fluorescein phosphoramidite (FAM; peak emission at $490 \mathrm{~nm}$ and peak excitation at $530 \mathrm{~nm}$ ) and Redmond Red phosphoramidite (peak emission at $579 \mathrm{~nm}$ and peak excitation at $595 \mathrm{~nm}$ ), respectively. Additionally, both primers were modified at the $5^{\prime}$ end with iso-dC. Primers VertBt-F and PotAct-F were not labeled or modified. Amplifications were performed in $25-\mu$ l reactions with $200 \mathrm{nM}$ each primer, and using Plexor master mix (Promega Corp.). The following amplification protocol was used: initial denaturation of $2 \mathrm{~min}$ at $95^{\circ} \mathrm{C}$, followed by 40 cycles of $95^{\circ} \mathrm{C}$ for $5 \mathrm{~s}$ and $61^{\circ} \mathrm{C}$ for 35 s. Unlike the TaqMan technology (Applied Biosystems), Plexor is amenable to melt curve analysis to distinguish potential nonspecific amplification products, including primer dimers.

Data analyses. To compare the results of the Q-PCR assay with colony counts, Spearman correlations were calculated using PROC CORR in SAS on both air-dried and fresh samples. A rejection of the null hypothesis $(P$ value $<0.05)$ would indicate a lack of significant difference between IC versus CFU of $V$. dahliae.

\section{RESULTS}

Primer design, specificity, sensitivity, and efficiency. All sequences from strains of one species were monomorphic regardless of the host they were isolated from or geographic origin. Sequences of act, efl- $\alpha, H 3, H 4, \beta$-tubulin 1 , and cal did not provide the needed polymorphisms to differentiate $V$. dahliae from the other species, especially $V$. tricorpus and V. albo-atrum. Conversely, sequences of $\beta$-tubulin 2 provided polymorphisms that separated $V$. dahliae closely from related species (e.g., V. alboatrum and $V$. tricorpus), and these sequences were used to generate primers specific to $V$. dahliae.

The primer pair VertBt-F/VertBt-R amplified a 115-bp region and was designed from the sequence of $\beta$-tubulin 2 (Table 2), which provided high specificity to isolates of $V$. dahliae obtained from various locations and crops (Table 1). This primer pair did not amplify any of the 9 other Verticillium spp., 15 Fusarium spp. or pathogens of potato or rotational crops tested in this study (Table 1). Melt curve analysis indicated the presence of a single amplification product. This amplified product was cloned into a TOPO TA vector, and sequence analysis exhibited identity with the expected 115-bp target region in the $\beta$-tubulin gene (data not shown).

Primer efficiency exceeded $96 \%$ over six orders of magnitude of $V$. dahliae DNA concentration, when only DNA from pure culture was used (Table 3; Fig. 1). Furthermore, the efficiency exceeded $95 \%$ in the presence of $25 \mathrm{ng}$ of potato DNA (Table 3;
Fig. 1). The comparison of the slopes of both equations using ANCOVA indicated no significant difference $(P=0.9255)$ in the efficiency of the designed primer regardless of the presence of host DNA. The lowest concentration of $V$. dahliae DNA reliably amplified was $148 \mathrm{fg}\left(1.48 \times 10^{-6} \mathrm{ng}\right)$ (Table 3). Lower concentrations of target DNA could not be quantified consistently.

Q-PCR amplifications of fresh greenhouse samples and airdried field samples. $\Delta \mathrm{Ct}$ values ranged from -0.2 to +0.2 when fresh potato tissues were used, and ranged from -0.6 to +0.7 when air-dried tissues were used to extract DNA. The ranges are within the variability of iCycler IQ real-time PCR system. Hence, corrections of the $\mathrm{Ct}$ values were not needed.

Of the 12 inoculated Russet Norkotah plants, 10 were found to harbor $V$. dahliae when tested with Q-PCR and NPX plating assays (Table 4). Two plants escaped infection with $V$. dahliae and tested negative for $V$. dahliae using both assays. None of the Ranger Russet plants harbored the pathogen (Table 4). The Spearman correlation coefficient used to compare the CFU counts and IC was highly significant $\left(R^{2}=0.824\right.$ and $\left.P=0.0005\right)$. All the other plants that were left to go to maturity exhibited typical PED symptoms and died $\approx 2$ to 3 weeks earlier than noninoculated plants.

All 112 air-dried interspecific potato hybrid samples evaluated in the field were infected with $V$. dahliae when tested with Q-PCR (Fig. 2). In comparison, 11 of the 112 samples tested negative with NPX plating assay $(\approx 10 \%)$ (Fig. 2). The Spearman correlation coefficient on all 112 samples was highly significant $\left(R^{2}=\right.$ 0.703 and $P<0.0001)$. When the 11 samples that tested positive with the Q-PCR and negative with the plating assay were excluded from the Spearman correlation analysis, the coefficient remained highly significant $\left(R^{2}=0.653\right.$ and $\left.P<0.0001\right)$.

Primer duplexing. $V$. dahliae and $S$. tuberosum DNA were amplified simultaneously using the two labeled and modified primer pairs using the Plexor Q-PCR System. Primer efficiencies over 5 orders of magnitude of serial dilution of DNA concentration remained elevated and were not affected by the duplexing and were $97 \%$ efficient for VertBt-F/VertBt-R and $98 \%$ efficient for PotAct-F/PotAct-R (Fig. 3).

\section{DISCUSSION}

Since the early 1980s, most studies aimed at quantifying the colonization of potato tissues with $V$. dahliae have relied on CFUcounting assays on culture media. Such plating methods were used to differentiate among cultivars and breeding lines in the

TABLE 3. Cycle threshold $(\mathrm{Ct})$ values from six-point serial dilutions of Verticillium dahliae DNA from pure cultures in the presence or absence of potato (Solanum tuberosum) DNA

\begin{tabular}{lcc}
\hline & \multicolumn{2}{c}{ Ct values for potato DNA added (25ng) } \\
\cline { 2 - 3 }$V$. dahliae DNA amount & No & Yes \\
\hline $14.8 \mathrm{ng}$ & 18.6 & 18.4 \\
$1.48 \mathrm{ng}$ & 21.1 & 20.3 \\
$148 \mathrm{pg}$ & 24.6 & 24.5 \\
$14.8 \mathrm{pg}$ & 28.3 & 28.0 \\
$1.48 \mathrm{pg}$ & 31.7 & 31.5 \\
$148 \mathrm{fg}$ & 35.4 & 35.3 \\
Efficiency $^{\mathrm{a}}(\%)$ & 96.1 & 95.2 \\
\hline
\end{tabular}

a Real-time quantitative polymerase chain reaction efficiency values.

TABLE 2. Primers developed to detect and quantify Verticillium dahliae and Solanum tuberosum (potato) DNA

\begin{tabular}{|c|c|c|c|}
\hline Target organism & Gene target & Primer & Sequence \\
\hline \multirow[t]{2}{*}{ Verticillium dahliae } & $\beta$-tubulin & VertBt-F & AAC AAC AGT CCG ATG GAT AAT TC \\
\hline & $\ldots$ & VertBt-R & GTA CCG GGC TCG AGA TCG \\
\hline \multirow[t]{2}{*}{ Solanum tuberosum } & act & PotAct-F & TGA ACA CGG AAT TGT CAG CA \\
\hline & $\ldots$ & PotAct-R & GGG GTT AAG AGG GGC TTC AG \\
\hline
\end{tabular}


selection for and study of resistance to PED (10,14,17,25-28, $45,62)$. Those assays were also employed to describe the epidemiology of the disease and colonization by the pathogen under various agricultural and environmental conditions (2-4,15,16,18, $19,24,40,43,48,52,61)$. Expression of PED symptoms is greatly affected by environmental and agricultural conditions (e.g., weather during the growing season, irrigation frequency, and nitrogen fertilization), and selection of breeding lines based solely on symptoms is generally discouraged. In this study, we developed an effective Q-PCR alternative to the tedious and timeconsuming plating assays. NPX plates are incubated for at least 2 weeks and the medium allows for the growth of other species in the genus Verticillium (e.g., V. albo-atrum and V. tricorpus), which complicates pathogen quantification. Another complicating factor lies in the stochastic nature of the quantification using CFU counts, where a high variability within replicates of one sample commonly is observed (41). Furthermore, competition among colonies may affect $V$. dahliae quantification on culture media.

The sensitivity of detection of $V$. dahliae is greatly improved by the use of a PCR assay, as demonstrated by Li et al. (33), to detect as few as 50 target copies, and by Mahuku and Platt (35), who detected a larger number of microsclerotia. In this study, we were able to detect $148 \mathrm{fg}$ of $V$. dahliae nuclear DNA using Q-PCR (Table 3), which is equivalent to approximately five haploid genomes of Aspergillus nidulans (5) or $V$. dahliae from noncruciferous hosts (9). With the knowledge that the $\beta$-tubulin gene is present in a single copy in the nuclear genome of fungi (42), these results indicate that the sensitivity of our Q-PCR assays allows for the detection of as few as five nuclei of $V$. dahliae, which is at least one order of magnitude lower than other PCR-based assays described in the literature $(33,35)$. Other PCR-based approaches to quantify $V$. dahliae DNA relied on a visual end-point comparison of PCR-product band intensity on agarose gel to quantify $V$. dahliae by comparison with an internal control plasmid (13). The methodology described in the current study relies on a direct and real-time quantification of the DNA of $V$. dahliae, with no need to estimate DNA amounts against those of internal controls, and does not call for the use of gel electrophoresis. Also, the current approach provides for a means to compare amounts of host and pathogen DNA simultaneously, which other studies have not developed.
The primer pair VertBt-F/Vert-R exhibited high specificity to $V$. dahliae regardless of geographic origin or host plant infected (Table 1). Moreover, DNA from related species such as V. alboatrum and $V$. tricorpus, and from other fungal and oomycetous pathogens, was not amplifiable with VertBt-F/Vert-R. We tried mixing known amounts of $V$. dahliae DNA with DNA from Phytophthora infestans, $P$. erythroseptica, Pythium ultimum, Erwinia carotovora subsp. carotovora and subsp. atroseptica (syn. Pectobacterium carotovorum and $P$. atrosepticum, respectively), and Fusarium sambucinum, but failed to measure significant deviation in $\mathrm{Ct}$ values compared with $V$. dahliae alone (data not shown). Additionally, the primer pair was used successfully to detect $V$. dahliae from several Verticillium-wilt-symptomatic samples of ash (Fraxinus sp.), maple (Acer sp.), and other ornamental species (data not shown). Although this study is aimed specifically at the detection and quantification of $V$. dahliae in potato tissues, the described primer pair VertBt-F/VertBt-R potentially could be used for similar quantifications in other hosts. This is especially true when considering that the origin of many of the V. dahliae isolates used to generate these primers were nonsolanaceous hosts. The primer pair also was successful in detecting $V$. dahliae in potato tubers showing typical $V$. dahliae-associated symptoms on the stem end section, as well as others not showing symptoms but collected from plants that exhibited PED symptoms (data not shown).

Results of the Q-PCR assay were highly correlated with CFU counts obtained from air-dried $\left(R^{2}=0.82\right.$ and $\left.P=0.0005\right)$ and fresh potato stem samples $\left(R^{2}=0.70 \%\right.$ and $\left.P<0.0001\right)$. The results indicate that both methods are comparable in their ability to quantify $V$. dahliae. Nevertheless, Q-PCR amplifications of the two samples of infected potato tissues showed higher consistency of quantification compared with CFU counts. Similar to other related studies, the variability between the two samples tested by CFU counts was high $(35,41)$, with the standard deviation on the CFU counts reaching 346 with a mean of 212 (data not shown). Conversely, Ct values from both DNA samples using Q-PCR fluctuated by \pm 0.5 , which is within the normal variation of the iCycler iQ system, and a similar range of variation observed among the three amplification replicates from each DNA sample. Precision in quantification of the pathogen is critical for the selection of potato breeding lines and interspecific hybrids by breeders.
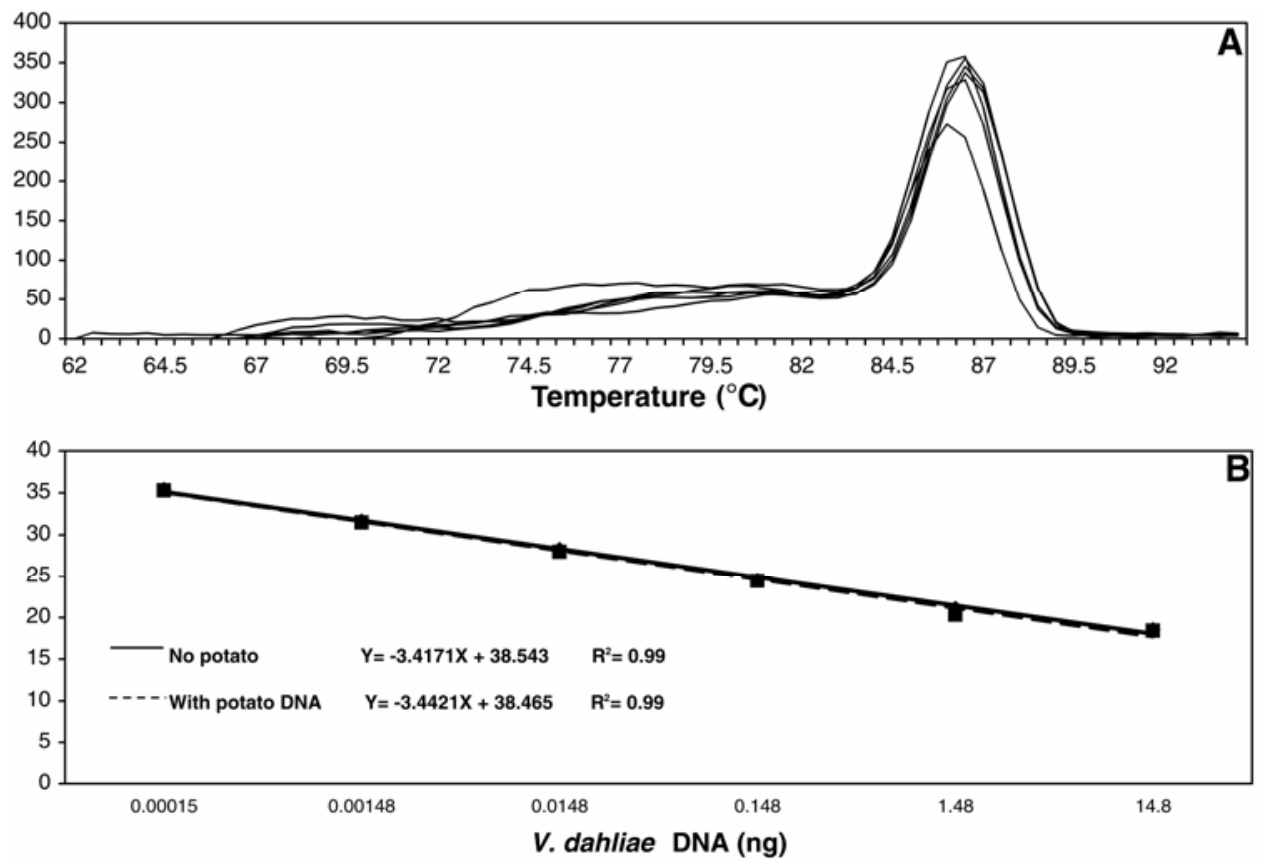

Fig. 1. A, Melt curve and B, efficiency curves of a six-point 10-fold serial dilution of Verticillium dahliae DNA in the presence or absence of potato DNA. Slopes of the efficiency curves are compared using analysis of covariance. RFU = relative fluorescence unit. 
Additionally, for $\approx 10 \%$ of the air-dried potato stems tested, NPX plating failed to detect the presence of $V$. dahliae, unlike Q-PCR (Fig. 2). In addition to the high variance in CFU counts, such a high rate of type II error (i.e., the inclusion of false negatives) may have a substantial impact on efforts to select potato breeding lines based on their colonization by $V$. dahliae.

The primer pairs VertBt-F/VertBt-R repeatedly exhibited efficiencies $>95 \%$ regardless of the presence or absence of large amounts of host DNA (Table 3; Fig. 1). The ANCOVA analysis on the slope of $V$. dahliae DNA alone (slope $=-3.417$ ) and of $V$. dahliae in the presence of $25 \mathrm{ng}$ of potato DNA (slope $=-3.442$ ) yielded an $F$ statistic of $7.01(P=0.9255)$ (Fig. 1). This indicates that the two slopes are not significantly different. Elevated efficiencies were measured over 6 orders of magnitude of DNA concentration exhibiting a linear dynamic range of amplification, with $R^{2}$ values exceeding 0.99 for both regression equations. Moreover, the duplexing of both primer pairs, using Plexor technology, did not have a significant impact on the efficiency of primer pairs VertBtF/Vert-Bt-R and PotAct-F/PotAct-R, used to quantify potato (Fig. 3 ). This high efficiency is crucial for meaningful quantifications of $V$. dahliae and for subsequent selections of germplasm.

In air-dried samples, $V$. dahliae is primarily in the form of microsclerotia, whereas it is in the vegetative form of conidia and

TABLE 4. Comparison of infection coefficient (IC) and CFU values 4 weeks postinoculation of 12 Ranger Russet (potato early dying [PED]-resistant) and 12 Russet Norkotah (PED-susceptible) cultivars ${ }^{a}$

\begin{tabular}{|c|c|c|c|c|}
\hline \multirow[b]{2}{*}{ Sample $^{b}$} & \multicolumn{2}{|c|}{$\mathrm{Ct}$ value ${ }^{\mathrm{c}}$} & \multirow[b]{2}{*}{$\mathrm{IC}^{\mathrm{d}}$} & \multirow[b]{2}{*}{$\mathrm{CFU}^{\mathrm{e}}$} \\
\hline & V. dahliae & Potato & & \\
\hline \multicolumn{5}{|c|}{ Ranger Russet } \\
\hline RR1 & NA & 22.7 & 0.0 & 0 \\
\hline RR2 & NA & 21.6 & 0.0 & 0 \\
\hline RR3 & NA & 22.4 & 0.0 & 0 \\
\hline RR4 & NA & 23.0 & 0.0 & 0 \\
\hline RR5 & NA & 23.5 & 0.0 & 0 \\
\hline RR6 & NA & 22.0 & 0.0 & 0 \\
\hline RR7 & NA & 22.1 & 0.0 & 0 \\
\hline RR8 & NA & 21.7 & 0.0 & 0 \\
\hline RR9 & NA & 21.5 & 0.0 & 0 \\
\hline RR10 & NA & 21.9 & 0.0 & 0 \\
\hline RR11 & NA & 22.2 & 0.0 & 0 \\
\hline RR12 & NA & 20.8 & 0.0 & 0 \\
\hline RRCtrl & NA & 20.5 & 0.0 & 0 \\
\hline \multicolumn{5}{|c|}{ Russet Norkotah } \\
\hline RN1 & 28.8 & 22.1 & 0.8 & 350 \\
\hline RN2 & 31.8 & 22.4 & 0.7 & 1,200 \\
\hline RN3 & 35.7 & 21.8 & 0.6 & 149 \\
\hline RN4 & NA & 21.7 & 0.0 & 0 \\
\hline RN5 & 36.8 & 22.4 & 0.6 & 7 \\
\hline RN6 & 29.0 & 21.1 & 0.7 & 704 \\
\hline RN7 & NA & 21.2 & 0.0 & 0 \\
\hline RN8 & 28.7 & 20.6 & 0.7 & 8 \\
\hline RN9 & 33.8 & 21.6 & 0.6 & 58 \\
\hline RN10 & 35.3 & 20.3 & 0.6 & 34 \\
\hline RN11 & 35.0 & 21.2 & 0.6 & 13 \\
\hline RN12 & 31.3 & 21.0 & 0.7 & 233 \\
\hline RNCtrl & NA & 21.5 & 0.0 & 0 \\
\hline
\end{tabular}

${ }^{a}$ Fresh stem samples weighing $50 \mathrm{mg}$ were used in the real-time quantitative polymerase chain reaction (Q-PCR) assay and $50 \mu \mathrm{l}$ of sap was used in the NPX plating assay. Inoculations were performed by dipping roots in a suspension of Verticillium dahliae (isolate V18) $\left(8 \times 10^{6}\right.$ conidia/ml). Spearman correlation comparing IC and CFU value: $R^{2}=0.824$ and $P=$ 0.0005. NA = no amplification.

b Control plants $(\mathrm{Ctrl})$ were dipped in water, and otherwise treated comparably to inoculated plants.

${ }^{\mathrm{c}} \mathrm{Ct}=$ cycle threshold. $V$. dahliae DNA was amplified using primer pair: VertBT-F/VertBT-R and potato (Solanum tuberosum) DNA was amplified using primer pair: PotAct-F/PotAct-R.

${ }^{\mathrm{d}} \mathrm{IC}=\mathrm{Ct}_{\text {potato }} / \mathrm{Ct}_{\text {V.dahliae }}$. Limit of $\mathrm{Ct}_{\text {potato }} / \mathrm{Ct}_{\text {V.dahliae }}$ when the denominator tends to infinity indicated by 0.0 . The number of Q-PCR amplification cycles is capped at 40 in the experiment.

e CFU as counted on the semiselective culture medium NPX. mycelia in fresh samples. Four weeks following inoculations, $V$. dahliae was detected in plants of Russet Norkotah, and no evidence of infection with the pathogen was detected in plants of Ranger Russet (PED resistant) (Table 4). The lack of detection of V. dahliae isolate V18 in two plants of Russet Norkotah (RN4 and RN7) indicates escapes from infection and subsequent colonization by the pathogen. There was no significant difference between CFU counts and IC values, which were highly correlated $\left(R^{2}=0.824\right.$ and $\left.P<0.0001\right)$. Both NPX plating and Q-PCR assays successfully identified plants RN4 and RN7 as negatives, which further bolsters the conclusion that both methods are biologically correlated. It is worth mentioning that no symptoms were observed on the infected plants in the greenhouse at the time of sampling. Plants that were inoculated with $V$. dahliae isolate V18 at the same time and raised to maturity showed typical PED symptoms and died 2 to 3 weeks earlier than noninoculated control plants.

In this study, we demonstrated the effectiveness of real-time QPCR assays for the detection and quantification of $V$. dahliae in plant tissues. A primer pair (VertBt-F/VertBt-R) was designed that

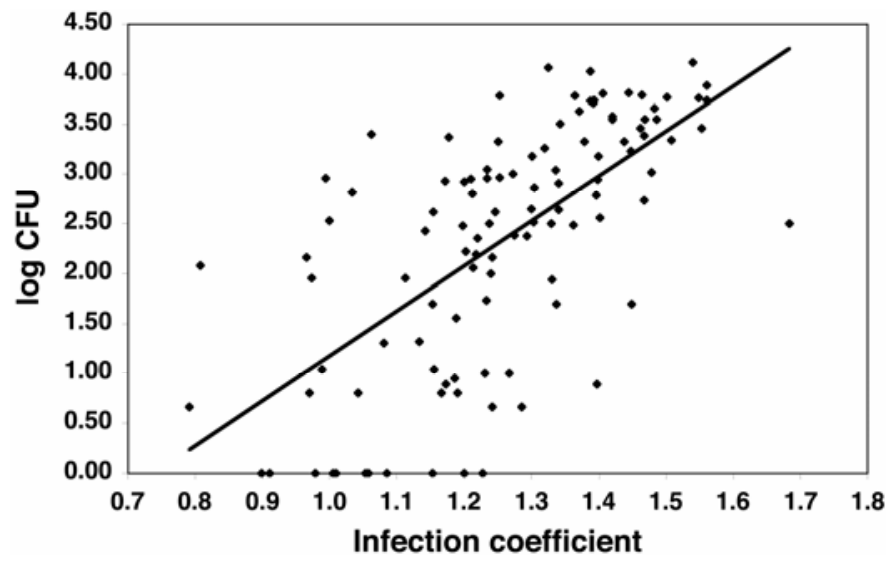

Fig. 2. Comparison of infection coefficient $(\mathrm{IC}=$ cycle threshold $\left.[\mathrm{Ct}]_{\text {host }} / \mathrm{Ct}_{\text {pathogen }}\right)$ and $\log \mathrm{CFU}$ in $50-\mathrm{mg}$ samples of air-dried stems of Solanum hybrids planted in a Verticillium dahliae-infested potato field and infested with $V$. dahliae-colonized rye kernels (200 CFU/g).
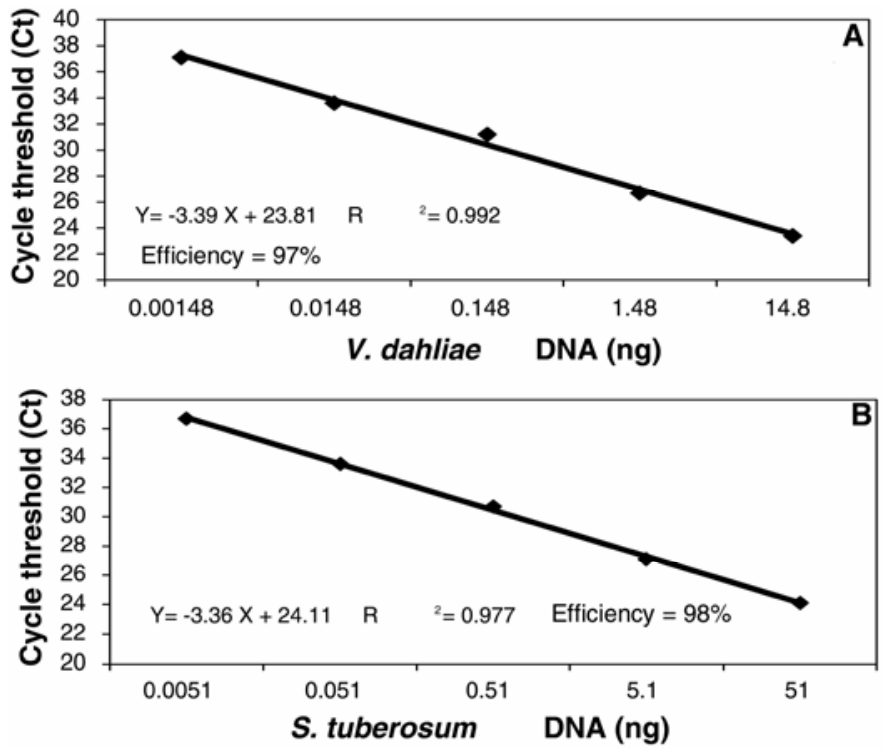

Fig. 3. Real-time quantitative polymerase chain reaction (Q-PCR) efficiency curves of a five-point serial dilution of DNA from A, Verticillium dahliae and B, Solanum tuberosum amplified in duplex using Plexor Q-PCR System (Promega Corp., Madison, WI). 
selectively amplifies $V$. dahliae at DNA amounts of $148 \mathrm{fg}$ while exhibiting high efficiency over six orders of magnitude. The assay also permitted the detection of $V$. dahliae of infected stems that tested negative by plating. The Q-PCR procedure reduces the time needed for the detection and quantification of $V$. dahliae from 2 weeks to 1 day and it improves the accuracy of quantification compared with plating assays. Additionally, the VertBt-F/VertBt$\mathrm{R}$ primer pair provides an unambiguous detection of $V$. dahliae compared with the less discriminatory detection of multiple Verticillium spp. using plating assays. Further experiments currently are being conducted to identify the timing of infection, spatiotemporal distribution of the pathogen in the host, and the genetic mechanisms of susceptibility or resistance to $V$. dahliae in Ranger Russet and Russet Norkotah.

\section{ACKNOWLEDGMENTS}

This research was supported by grants from the United States Department of Agriculture-Agricultural Research Service Potato Research Program and the Wisconsin Potato and Vegetable Growers Association to Z. K. Atallah and W. R. Stevenson. We thank L. du Toit for her thorough and meticulous presubmission review of this manuscript, and the senior editor and anonymous reviewers of Phytopathology for helping to improve this manuscript.

\section{LITERATURE CITED}

1. Atallah, Z. K., and Stevenson, W. R. 2006. A methodology to detect and quantify five pathogens causing potato tuber decay using real-time quantitative PCR. Phytopathology 96:1037-1045.

2. Bowden, R. L., and Rouse, D. I. 1987. Effects of Verticillium dahliae on photosynthesis and transpiration of potato. Phytopathology 77:1703-1703.

3. Bowden, R. L., and Rouse, D. I. 1991. Effects of Verticillium dahliae on gas exchange of potato. Phytopathology 81:293-301.

4. Bowden, R. L., Rouse, D. I., and Sharkey, T. D. 1990. Mechanism of photosynthesis decrease by Verticillium dahliae in potato. Plant Physiol. 94:1048-1055.

5. Brody, H., and Carbon, J. 1989. Electrophoretic karyotype of Aspergillus nidulans. Proc. Natl. Acad. Sci. USA 86:6260-6263.

6. Butterfield, E. J., and Devay, J. E. 1977. Reassessment of soil assays for Verticillium dahliae. Phytopathology 67:1073-1078.

7. Carbone, I., and Kohn, L. M. 1999. A method for designing primer sets for speciation studies in filamentous Ascomycetes. Mycologia 91:553556.

8. Cochran, W. G., and Cox, G. M. 1957. Experimental Designs, 2nd ed. John Wiley and Sons, New York

9. Collins, A., Okoli, C. A. N., Morton, A., Parry, D., Edwards, S. G., and Barbara, D. J. 2003. Isolates of Verticillium dahliae pathogenic to crucifers are of at least three distinct molecular types. Phytopathology 93:364376.

10. Corsini, D. L., Pavek, J. J., and Davis, J. R. 1990. Verticillium wilt resistant potato germplasm-A66107-51 and A68113-4. Am. Potato J. 67:517525.

11. Cullen, D. W., Lees, A. K., Toth, I. K., and Duncan, J. M. 2001. Conventional PCR and real-time quantitative PCR detection of Helminthosporium solani in soil and on potato tubers. Eur. J. Plant Pathol. 107:387-398.

12. Cullen, D. W., Lees, A. K., Toth, I. K., and Duncan, J. M. 2002. Detection of Colletotrichum coccodes from soil and potato tubers by conventional and quantitative real-time PCR. Plant Pathol. 51:281-292.

13. Dan, H., Ali-Khan, S. T., and Robb, J. 2001. Use of quantitative PCR diagnostics to identify tolerance and resistance to Verticillium dahliae in potato. Plant Dis. 85:700-705.

14. Davis, J. R., Pavek, J. J., and Corsini, D. L. 1983. A sensitive method for quantifying Verticillium dahliae colonization in plant tissue and evaluating resistance among potato genotypes. Phytopathology 73:1009-1014.

15. Davis, J. R., Pavek, J. J., Corsini, D. L., Sorensen, L. H., Schneider, A. T., Everson, D. O., Westermann, D. T., and Huisman, O. C. 1994. Influence of continuous cropping of several potato clones on the epidemiology of Verticillium wilt of potato. Phytopathology 84:207-214

16. Davis, J. R., and Sorensen, L. H. 1986. Benefits and problems associated with metam-sodium treatments on potato. Am. Potato J. 63:418-419.

17. Davis, J. R., and Sorensen, L. H. 1986. Differential effects of potato genotype and metam sodium on the population dynamics of Verticillium spp. Phytopathology 76:1094-1094.

18. Davis, J. R., Sorensen, L. H., Corsini, D. L., and Hafez, S. L. 1983. Effects of continuous cropping with potato genotypes on Verticillium dahliae and Pratylenchus neglectus. Phytopathology 73:958-958.

19. Davis, J. R., Sorensen, L. H., Stark, J. C., and Westermann, D. T. 1990. Fertility and management-practices to control Verticillium wilt of the Russet Burbank potato. Am. Potato J. 67:55-65.

20. Frackman, S., Ekenberg, S., Hoffmann, K., Krenke, B., Sprecher, C., and Storts, D. 2005. Plexor technology: A new chemistry for real-time PCR. Promega Notes 90:2-4.

21. Gao, X., Jackson, T. A., Lambert, K. N., Li, S., Hartman, G. L., and Niblack, T. L. 2004. Detection and quantification of Fusarium solani f. sp. glycines in soybean roots with real-time quantitative polymerase chain reaction. Plant Dis. 88:1372-1380.

22. Glass, N. L., and Donaldson, G. C. 1995. Development of primer sets designed for use with the PCR to amplify conserved genes from filamentous Ascomycetes. Appl. Environ. Microbiol. 61:1323-1330.

23. Hall, T. A. 1999. BioEdit: a user-friendly biological sequence alignment editor and analysis program for Windows 95/98/NT. Nucleic Acid Symp. Ser. 41:95-98.

24. Hamm, P. B., Ingham, R. E., Jaeger, J. R., Swanson, W. H., and Volker, K. C. 2003. Soil fumigant effects on three genera of potential soilborne pathogenic fungi and their effect on potato yield in the Columbia Basin of Oregon. Plant Dis. 87:1449-1456.

25. Hoyos, G. P., Lauer, F. I., and Anderson, N. A. 1993. Early detection of Verticillium wilt resistance in a potato breeding program. Am. Potato J. 70:535-541.

26. Jansky, S., Rouse, D. I., and Kauth, P. J. 2004. Inheritance of resistance to Verticillium dahliae in diploid interspecific potato hybrids. Plant Dis. 88:1075-1078

27. Jansky, S. H., and Rouse, D. I. 2000. Identification of potato interspecific hybrids resistant to Verticillium wilt and determination of criteria for resistance assessment. Potato Res. 43:239-251.

28. Jansky, S. H., and Rouse, D. I. 2003. Multiple disease resistance in interspecific hybrids of potato. Plant Dis. 87:266-272.

29. Jeger, M. J., Hide, G. A., VandenBoogert, P., Termorshuizen, A. J., and VanBaarlen, P. 1996. Pathology and control of soil-borne fungal pathogens of potato. Potato Res. 39:437-469.

30. Kimpinski, J., Platt, H. W., Perley, S., and Walsh, J. R. 1998. Pratylenchus spp. and Verticillium spp. in New Brunswick potato fields. Am. J. Potato Res. 75:87-91.

31. Ko, K. S., and Jung, H. S. 2002. Three nonorthologous ITS1 types are present in a polypore fungus Trichaptum abietinum. Mol. Phylogenet. Evol. 23:112-122.

32. Lees, A. K., Cullen, D. W., Sullivan, L., and Nicolson, M. J. 2002. Development of conventional and quantitative real-time PCR assays for the detection and identification of Rhizoctonia solani AG-3 in potato and soil. Plant Pathol. 51:293-302.

33. Li, K. N., Rouse, D. I., Eyestone, E. J., and German, T. L. 1999. The generation of specific DNA primers using random amplified polymorphic DNA and its application to Verticillium dahliae. Mycol. Res. 103:13611368.

34. Lynch, D. R., Chen, Q., Kawchuk, L. M., and Driedger, D. 2004. Verticillium wilt resistant germplasm-release of clone LRC18-21 and derivatives. Am. J. Potato Res. 81:295-297.

35. Mahuku, G. S., and Platt, H. W. 2002. Quantifying Verticillium dahliae in soils collected from potato fields using a competitive PCR assay. Am. J. Potato Res. 79:107-117.

36. Mahuku, G. S., Platt, H. W., and Maxwell, P. 1999. Comparison of polymerase chain reaction based methods with plating on media to detect and identify Verticillium wilt pathogens of potato. Can. J. Plant Pathol. 21:125-131.

37. Mercado-Blanco, J., Rodriguez-Jurado, D., Parrilla-Araujo, S., and Jimenez-Diaz, R. M. 2003. Simultaneous detection of the defoliating and nondefoliating Verticillium dahliae pathotypes in infected olive plants by duplex, nested polymerase chain reaction. Plant Dis. 87:14871494.

38. Mohan, S. K., Davis, J. R., Corsini, D. L., Sorensen, L. H., and Pavek, J. J. 1987. Comparison of methods for evaluation of potato genotypes for resistance to Verticillium wilt. Phytopathology 77:1702-1702.

39. Mohan, S. K., Davis, J. R., Corsini, D. L., Sorensen, L. H., and Pavek, J. J. 1990. Reaction of potato clones and accessions of Solanum spp. to Verticillium dahliae Kleb and its toxin. Potato Res. 33:449-458.

40. Morgan, G. D., Stevenson, W. R., MacGuidwin, A. E., Kelling, K. A., Binning, L. K., and Zhu, J. 2002. Plant pathogen population dynamics in potato fields. J. Nematol. 34:189-193.

41. Mpofu, S. I., and Hall, R. 2003. Accuracy and precision of population estimates of Verticillium dahliae on growth media in quantitative soil assays. Can. J. Bot. (Rev. Can. Bot.) 81:294-306.

42. Nahimana, A., Francioli, P., Blanc, D. S., Bille, J., Wakefield, A. E., and Hauser, P. M. 2000. Determination of the copy number of the nuclear rDNA and beta-tubulin genes of Pneumocystis carinii f. sp hominis using PCR multicompetitors. J. Eukaryot. Microbiol. 47:368-372. 
43. Nicot, P. C., and Rouse, D. I. 1987. Relationship between soil inoculum density of Verticillium dahliae and systemic colonization of potato stems in commercial fields over time. Phytopathology 77:1346-1355.

44. Paris, R., and Lamattina, L. 2002. Increased ratio of mitochondrial rDNA to cytoplasmic rDNA during zoosporic and germinating cyst stages of the life cycle of Phytophthora infestans (Mont.) de Bary. Can. J. Microbiol. 48:268-274.

45. Pegg, G. F., and Street, P. F. S. 1984. Measurement of Verticillium alboatrum in high and low resistance hop cultivars. Trans. Br. Mycol. Soc. 82:99-106.

46. Powelson, M. L., and Rowe, R. C. 1993. Biology and management of early dying of potatoes. Annu. Rev. Phytopathol. 31:111-126.

47. Ristaino, J. B., Madritch, M., Trout, C. L., and Parra, G. 1998. PCR amplification of ribosomal DNA for species identification in the plant pathogen genus Phytophthora. Appl. Environ. Microbiol. 64:948-954.

48. Rowe, R. C., Davis, J. R., Powelson, M. L., and Rouse, D. I. 1987. Potato early dying-causal agents and management strategies. Plant Dis. 71:482489.

49. Rowe, R. C., and Powelson, M. L. 2002. Potato early dying: management challenges in a changing production environment. Plant Dis. 86:11841193.

50. Rozen, S., and Skaletsky, H. 2000. Primer3 on the WWW for general users and for biologist programmers. Pages 365-386 in: Bioinformatics Methods and Protocols: Methods in Molecular Biology. S. Krawetz and S. Misener, eds. Humana Press, Totowa, NJ

51. Sadras, V. O., Quiroz, F., Echarte, L., Escande, A., and Pereyra, V. R. 2000. Effect of Verticillium dahliae on photosynthesis, leaf expansion and senescence of field-grown sunflower. Ann. Bot. 86:1007-1015.

52. Saeed, I. A. M., MacGuidwin, A. E., Rouse, D. I., and Sharkey, T. D. 1999. Limitation to photosynthesis in Pratylenchus penetrans- and Verticillium dahliae-infected potato. Crop Sci. 39:1340-1346.

53. Schweigkofler, W., O'Donnell, K., and Garbelotto, M. 2004. Detection and quantification of airborne conidia of Fusarium circinatum, the causal agent of pine pitch canker, from two California sites by using a real-time PCR approach combined with a simple spore trapping method. Appl. Environ. Microbiol. 70:3512-3520.

54. Thompson, J. D., Gibson, T. J., Plewniak, F., Jeanmougin, F., and Higgins, D. G. 1997. The CLUSTAL_X windows interface: Flexible strategies for multiple sequence alignment aided by quality analysis tools. Nucleic Acids Res. 25:4876-4882.
55. Thompson, J. D., Higgins, D. G., and Gibson, T. J. 1994. Clustal-WImproving the sensitivity of progressive multiple sequence alignment through sequence weighting, position-specific gap penalties and weight matrix choice. Nucleic Acids Res. 22:4673-4680.

56. Tooley, P. W., Bunyard, B. A., Carras, M. M., and Hatziloukas, E. 1997. Development of PCR primers from internal transcribed spacer region 2 for detection of Phytophthora species infecting potatoes. Appl. Environ. Microbiol. 63:1467-1475.

57. Tooley, P. W., Carras, M. M., and Lambert, D. H. 1998. Application of a PCR-based test for detection of potato late blight and pink pot in tubers. Am. J. Potato Res. 75:187-194.

58. Trout, C. L., Ristaino, J. B., Madritch, M., and Wangsomboondee, T. 1997. Rapid detection of Phytophthora infestans in late blight-infected potato and tomato using PCR. Plant Dis. 81:1042-1048.

59. Valsesia, G., Gobbin, D., Patocchi, A., Vecchione, A., Pertot, I., and Gessler, C. 2005. Development of a high-throughput method for quantification of Plasmopara viticola DNA in grapevine leaves by means of quantitative real-time polymerase chain reaction. Phytopathology 95:672-678.

60. Wen, K., Seguin, P., St-Arnaud, M., and Jabaji-Hare, S. 2005. Real-time quantitative RT-PCR of defense-associated gene transcripts of Rhizoctonia solani-infected bean seedlings in response to inoculation with a nonpathogenic binucleate Rhizoctonia isolate. Phytopathology 95:345-353.

61. Wheeler, T. A., Madden, L. V., Rowe, R. C., and Riedel, R. M. 2000. Effects of quadrat size and time of year for sampling of Verticillium dahliae and lesion nematodes in potato fields. Plant Dis. 84:961-966.

62. Wheeler, T. A., Rowe, R. C., Riedel, R. M., and Madden, L. V. 1994. Influence of cultivar resistance to Verticillium spp. on potato early dying. Am. Potato J. 71:39-57.

63. Winton, L. M., Manter, D. K., Stone, J. K., and Hansen, E. A. 2003. Comparison of biochemical, molecular, and visual methods to quantify Phaeocryptopus gaeumannii in Douglas-Fir foliage. Phytopathology 93:121-126.

64. Winton, L. M., Stone, J. K., Watrud, L. S., and Hansen, E. M. 2002. Simultaneous one-tube quantification of host and pathogen DNA with real-time polymerase chain reaction. Phytopathology 92:112-116.

65. Zuker, M., Mathews, D. H., and Turner, D. H. 1999. Algorithms and Thermodynamics for RNA Secondary Structure Prediction: A Practical Guide in RNA Biochemistry and biotechnology. J. Barciszewski and B. F. C. Clark, eds. Kluwer Academic Publishers, Dordrecht, the Netherlands. 